Supplement of

\title{
Seismic noise variability as an indicator of urban mobility during the COVID-19 pandemic in the Santiago metropolitan region, Chile
}

\author{
Javier Ojeda and Sergio Ruiz \\ Correspondence to: Javier Ojeda (jojeda@dgf.uchile.cl)
}

The copyright of individual parts of the supplement might differ from the article licence. 
1 Additional information

This supplemental file contains Tables S1 and S2, and Figures S1, S2, S3, S4, and S5, mentioned in the manuscript. 
Table S1. Step by step gradual reopening of the country, presented as a public health policy to mitigate the virus spreading. Applicable only from 19 July 2020.

\begin{tabular}{|c|c|c|}
\hline Step & Name & Brief description \\
\hline Phase 1 & Quarantine & Full Lockdown. Only essential business allowed. \\
\hline Phase 2 & Transition & $\begin{array}{l}\text { Lockdown is maintained on weekends and holidays. Opening of shops and going to } \\
\text { work is allowed. Indoor gathering of up to five persons are permitted. }\end{array}$ \\
\hline Phase 3 & Preparation & $\begin{array}{l}\text { Open full week. Altough is not possible to transit to go to a quarantined place. Meet- } \\
\text { ings and events allowed for a max. of } 25 \text { people indoor and } 50 \text { people outdoor. } \\
\text { Restaurant and cafés allowed to work in open spaces but keeping social distance. }\end{array}$ \\
\hline Phase 4 & Initial opening & $\begin{array}{l}\text { Open full week. Cinema, theatres and similar may operate at } 25 \% \text { of their capacity. } \\
\text { School classes may return. }\end{array}$ \\
\hline Phase 5 & Advanced opening & $\begin{array}{l}\text { Open full week. Pubs, discotheques, gyms and similar may open up to } 50 \% \text { of their } \\
\text { capacity. }\end{array}$ \\
\hline
\end{tabular}

During the period analysed (1 Dec 2019 - 1 Oct 2020), none of the cities presented in this study advanced to Phase 4 or 5.

Table S2. Seismic stations used in this work, we added the information about location and dates when lockdown (LD) or other phases were implemented during the period analysed (1 Dec 2019 - 1 Oct 2020).

\begin{tabular}{|c|c|c|c|c|c|c|}
\hline Station & City & LD1 & end LD1 & LD2 & Phase 2 & Phase 3 \\
\hline MT01 & Daracena - Melipilla & 12 Jun & - & - & $10 \mathrm{Aug}$ & - \\
\hline MT02 & Curacaví & 12 Jun & - & - & 10 Aug & - \\
\hline MT03 & UAI - Peñalolén & 8 May & - & - & 24 Aug & $28 \mathrm{Sep}$ \\
\hline MT04 & Olivares & 12 Jun & - & - & 24 Aug & $2 \mathrm{Sep}$ \\
\hline MT05 & Cerro Colorado - Renca & 8 May & - & - & - & - \\
\hline MT07 & Cerro El Roble & 12 Jun & - & - & $28 \mathrm{Jul}$ & $28 \mathrm{Sep}$ \\
\hline MT08 & Bocatoma Colorado & 12 Jun & - & - & 24 Aug & $2 \mathrm{Sep}$ \\
\hline MT09 & Talagante & 26 Jun & - & - & 31 Aug & $28 \mathrm{Sep}$ \\
\hline MT10 & Hacienda Santa Martina & 15 May & - & - & $28 \mathrm{Jul}$ & - \\
\hline MT12 & Pirque & - & - & - & - & - \\
\hline MT13 & San Alfonso & 12 Jun & - & - & 24 Aug & 2 Sep \\
\hline MT14 & Cerro Calán - Las Condes & $26 \mathrm{Mar}$ & 16 Apr & 15 May & $28 \mathrm{Jul}$ & 2 Sep \\
\hline MT15 & Las Vizcachas & 8 May & - & - & $28 \mathrm{Sep}$ & - \\
\hline MT16 & CCHEN - Las Condes & $26 \mathrm{Mar}$ & 16 Apr & 15 May & $28 \mathrm{Jul}$ & 2 Sep \\
\hline MT18 & Casona - Santiago & $26 \mathrm{Mar}$ & $13 \mathrm{Apr}$ & 5 May & $17 \mathrm{Jul}$ & $28 \mathrm{Sep}$ \\
\hline TA02 & Iquique & 15 May & - & - & - & - \\
\hline $\mathrm{CO} 05$ & La Serena & $29 \mathrm{Jul}$ & - & - & $28 \mathrm{Sep}$ & - \\
\hline VA01 & Valparaíso & 12 Jun & - & - & - & - \\
\hline CCSP & San Pedro - Concepción & $6 \mathrm{Apr}$ & $16 \mathrm{Apr}$ & $11 \mathrm{Sep}$ & - & - \\
\hline MG01 & Puerto Williams & $25 \mathrm{Mar}$ & $6 \mathrm{Apr}$ & - & - & - \\
\hline
\end{tabular}

-: Not applicable dates during the period analysed. 

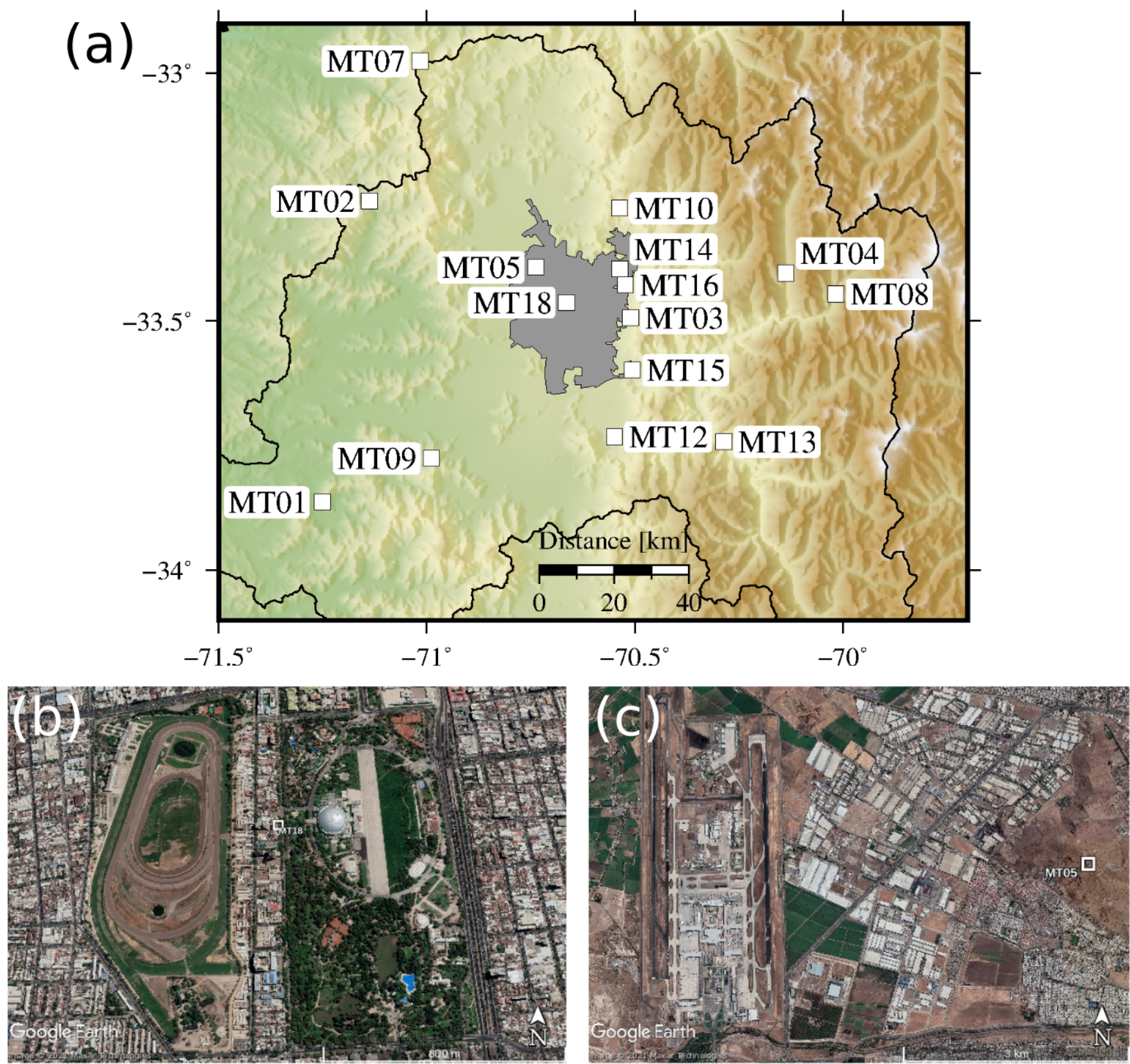

Figure S1. (a) Map of the Metropolitan region with 15 stations analysed in this study. Note that only stations MT05, MT18, MT14, MT16, MT03, and MT15 are stations in the Santiago city urban area (grey surface). (b) Close view to vicinity of MT18, in which we can see the hippodrome "Club Hípico de Santiago" on the left and the O'Higgins Park on the right. (c) Close view to the vicinity of MT05, in which we can see the Airport on the left. Photos from @Google Earth. 

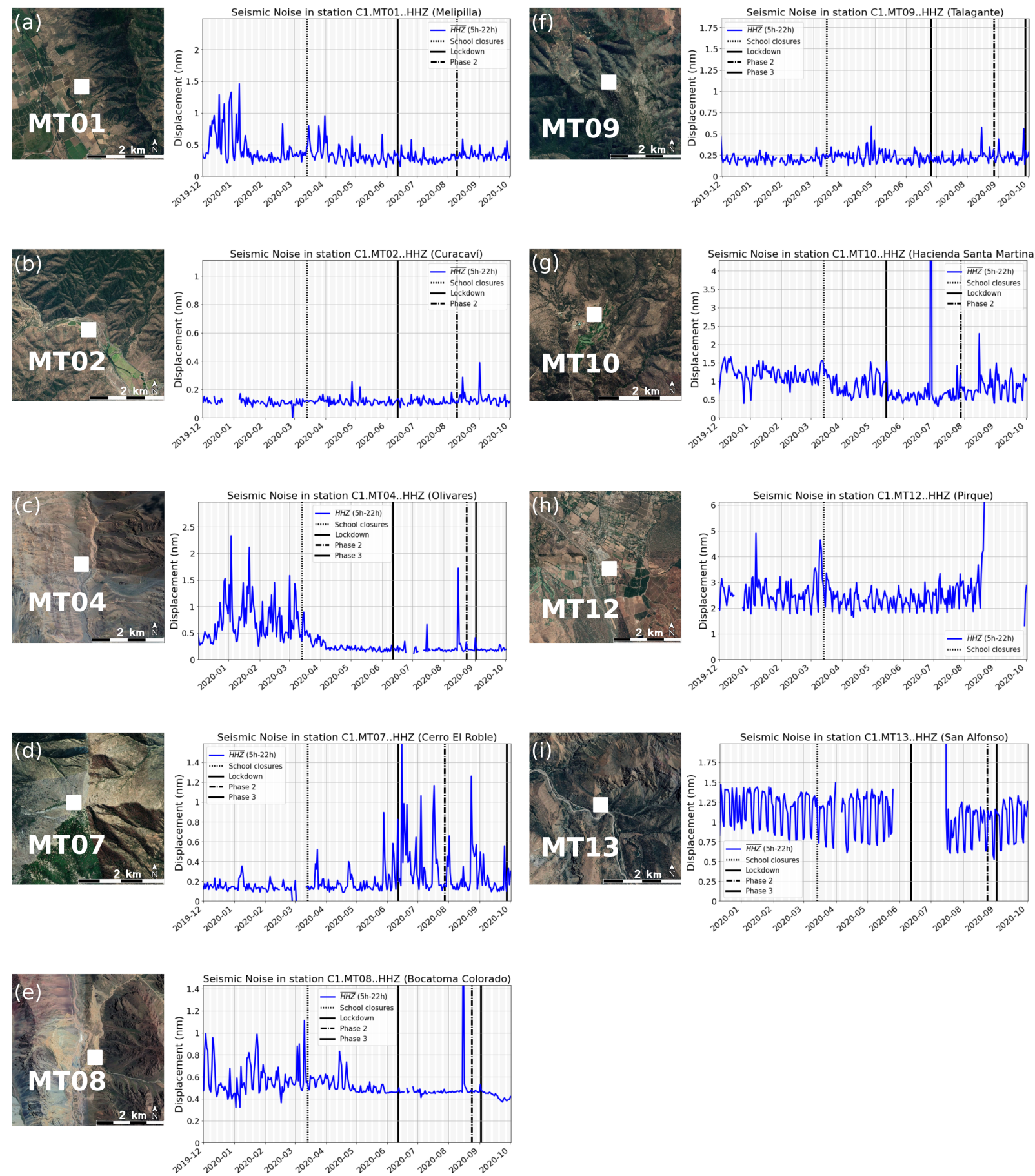

Figure S2. Changes in high-frequency seismic ambient noise amplitudes at stations (a) MT01, (b) MT02, (c) MT04, (d) MT07, (e) MT08, (f) MT09, (g) MT10, (h) MT12, and (i) MT13. The vertical black lines indicate the time of public restrictions implemented in the Metropolitan region. Each municipality inside the region had different lockdown periods or phases despite the proximity between them (see Table S2). Photos from (OGoogle Earth. 

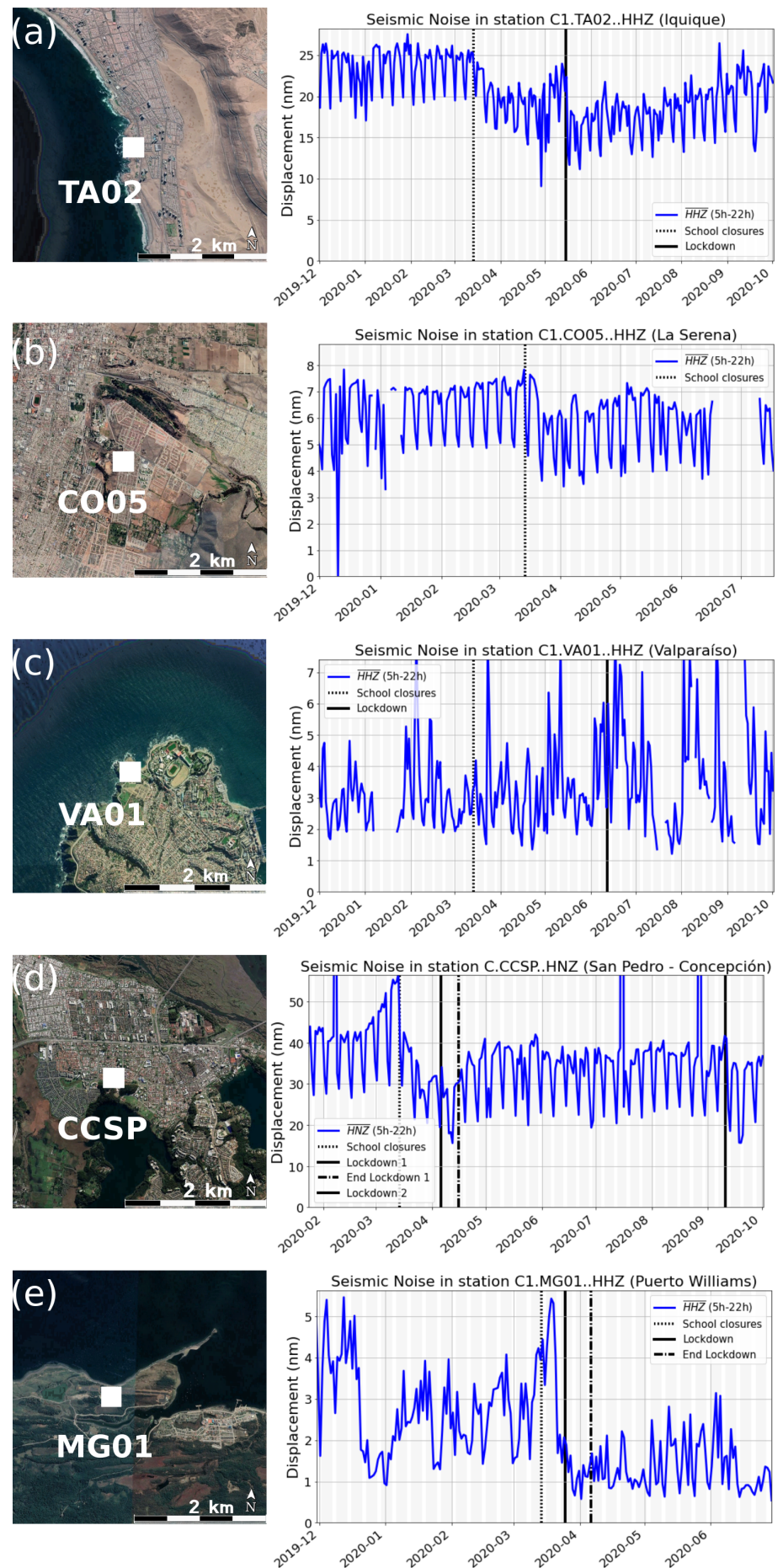

Figure S3. Changes in high-frequency seismic ambient noise amplitudes at stations (a) TA02, Iquique, (b) CO05, La Serena, (c) VA01, Valparaíso, (d) CCSP, San Pedro Concepción, and (e) MG01, Puerto Williams. The vertical black lines indicate the time of public restrictions implemented in each region. Photos from @Google Earth. 


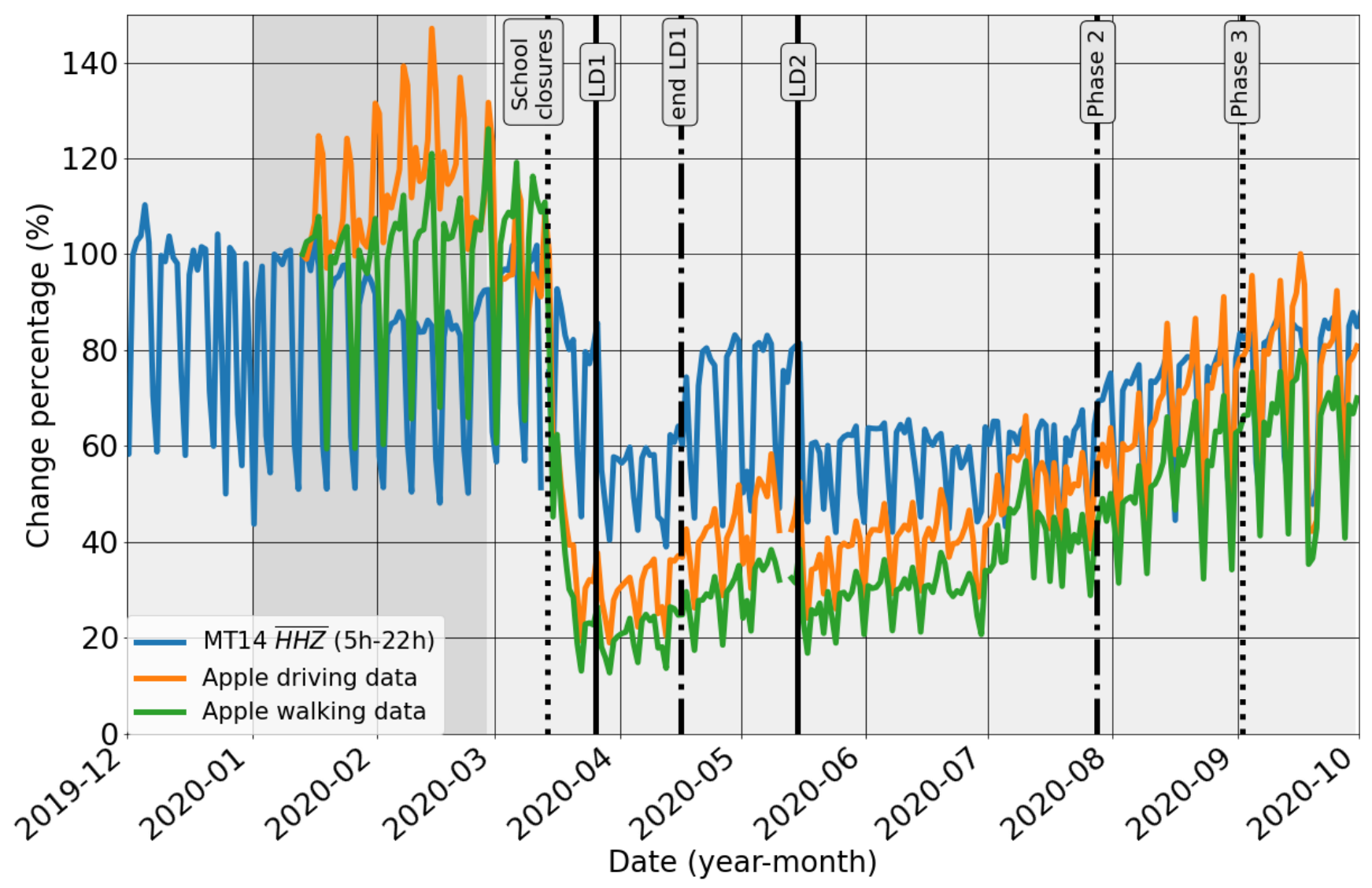

Figure S4. Comparison between noise evolution of station MT14 (blue line) and the Apple mobility data, specifically driving (orange line) and walking data (green line). The vertical black lines indicate the time of public restrictions implemented in Las Condes. The ASN amplitudes and Apple mobility data are normalised by a baseline value of the 13 January 2020. The grey background between January and March corresponds to the Summer holiday season in Chile. 


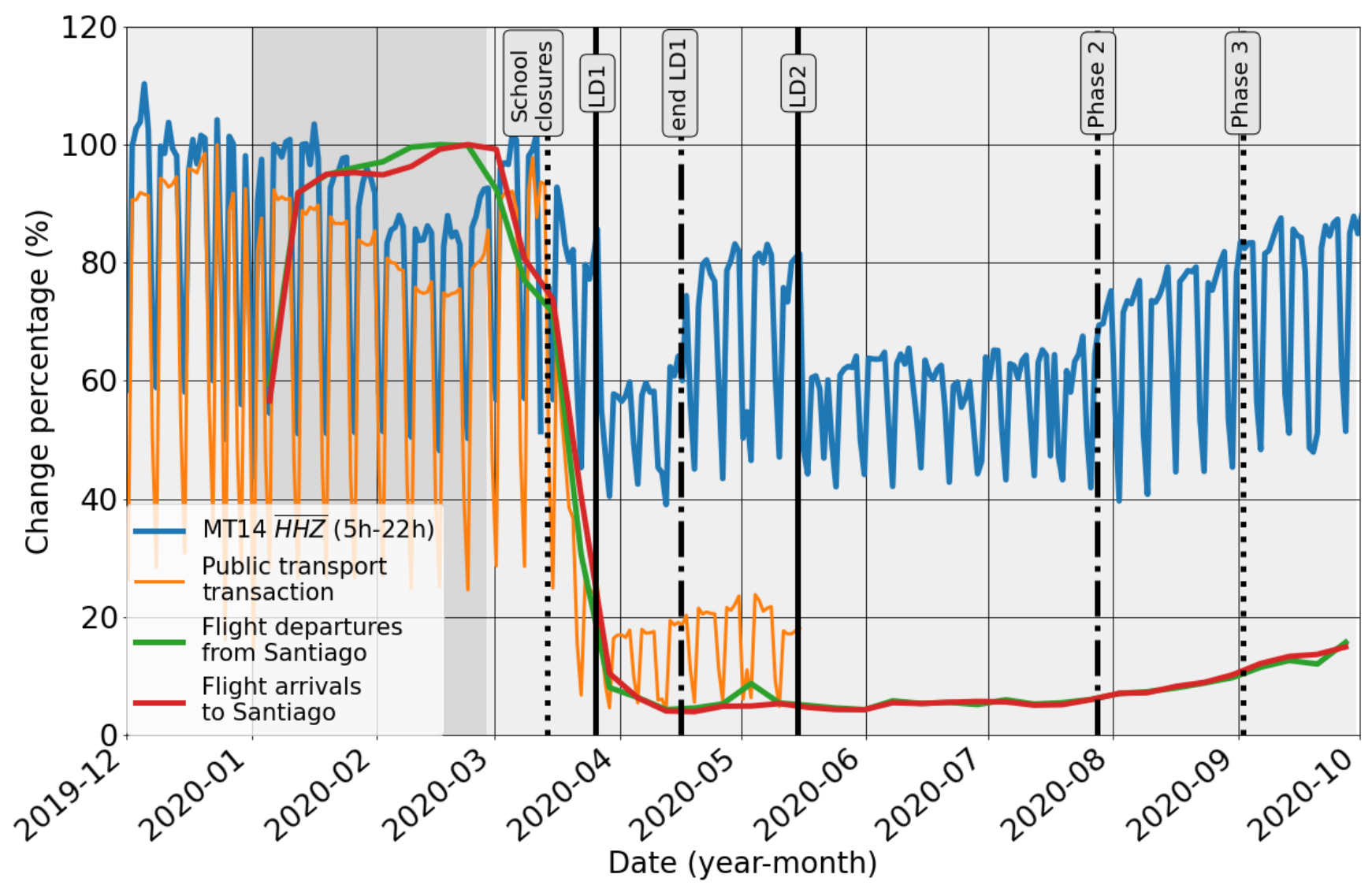

Figure S5. Comparison between noise evolution of station MT14 (blue line) and other mobility data, specifically public transport transactions (orange line), flight departures from Santiago (green line), and flight arrivals to Santiago (red line). The vertical black lines indicate the time of public restrictions implemented in Las Condes. The grey background between January and March corresponds to the Summer holiday season in Chile. 